\title{
TRAINING FUNCTIONAL TRANSLATORS
}

Christiane Nord

$M$ agdeburg

\section{General remarks}

Translator training institutions are shooting up like mushrooms all over the world, and even in the ordinary language classroom (e. g. , at culture institutions like the British Council, Institut $F$ rançais, Goethe-Institut or Instituto Cervantes) students are demanding some sort of basic training in (professional) translation. The problem is: Who is going to do the teaching? So far, there is no institutional training for translator trainers. Teachers of $M$ athematics or Philosophy are trained in their respective $F$ aculties, Language Teachers are trained in $M$ odern $L$ anguage $D$ epartments or F aculties of Second L anguage A cquisition, but persons applying for a position as translator trainer in a Faculty of Translation and Interpreting need no particular formal qualification, and if they needed one, they would not know where to get it. This does not mean that they are all bad translator trainers, but maybe life would be a little easier for them (and for their students?) if they had had some kind of special instruction and were not forced to re-invent the wheel of translation pedagogy over and over again.

I went into translator training about 35 years ago, two weeks after graduating as a translator. I had a few very inspired trainers (some had been trained as translators, others as language teachers, others were "just" native speakers with a juridical or technical background) - but did this qualify me for translator training? It didn't. 
At first I tried to imitate the teachers I had liked best in my own training, but then I felt this was not enough, and I started to develop my own teaching methodology. I presume that most novice translator trainers are still working along these lines today, and that, after years of practice, all their (positive or negative) experience and insights, their findings, their good ideas and original methods are oft interred with their bones.

To save my own insights and experience from this fate, I would like to expose them to discussion in the following article. A fter a brief outline of my theoretical starting-point (2.), I will first analyse what I consider to be the groundwork of any translational skills: intercultural competence (3.) and then proceed to discuss the relationship of practice and theory in translator training (4.). The three sections that follow will tackle very practical aspects of translator training: the selection of learning material (5.), teaching and learning methods (6.), and qual ity assessment (7.). To conclude, I will highlight a few areas where a cooperation between theory (i.e. research done by teachers or students) and practice (i.e. practising translators, commissioners, translation agencies, etc.) could be beneficial to and help make the training of the trainers a fully-fledged branch of applied translation studies.

\section{What is a "functional translator"?}

Talking about a "functional translator" is a very abbreviated form of describing a professional translator who:

a) is aware of the fact that, in today's translation practice, translations are needed for a variety of communicative functions (which are not always the same as that which the corresponding source text may have been intended to achieve) (= professional knowledge);

b) knows that the selection of linguistic and nonlinguistic signs which make up a text is guided by situational and cultural factors, 
and that this principle applies to both source and target-cultural text production ( = metacommunicative competence);

c) is able to spot the "rich points" (A gar 1991, 168), where the behaviour of the representatives of a particular pair of cultures or diacultures in a given situation is so divergent that it may lead to communication conflicts or even breakdowns, and finds ways and means to solve cultural conflicts without taking sides (= intercultural competence);

d) knows that, due to culture-specific conventions, apparently similar or analogous structures of two languages are not always used with the same frequency or in the same situation (= distribution) by the respective culture communities, and that the use of the wrong set of signs may severely interfere with the text's functionality;

e) has the ability to produce a target text serving the desired function even though the source text may be badly written or poorly reproduced (= writing abilities);

f) knows how to use both traditional and modern (i.e. electronic) translation aids and knowledge sources (= media competence);

g) has a good general education and a better specific knowledge of the topic the source text is about (or knows how to compensate efficiently for any lack of knowledge) (= research competence);

h) works fast, cost-efficiently, and to perfection, even under high pressure (= stress resistence), and

i) knows what her/his translations are worth (= self-assertion, from the practitioners' point of view, and self-assurance or selfconfidence, as the trainers see it).

This is the profile practitioners and theoreticians, or rather, trainers, more or less agreed upon at a Conference on Translation Quality which took place in Leipzig last year. Of course, the practitioners uttered a few more requirements, like skills in specific forms of translation (e.g. , dubbing, voice-over, website translation, software localization), management and leading competence, the ability to work in a team and to constantly adapt to changing working conditions, revision skills, and the like, and they could not 
make up their minds whether they preferred the generalist or the specialist as far as factual knowledge is concerned. The trainers, however, maintained the view that university training programmes must be general enough to enable their graduates to take up a broad range of activities, and specific enough to lay the foundations for a fast acquisition of any kind of special skills after graduation. On the whole, a functional translator is obviously a very versatile animal.

\section{Teaching intercultural competence: pre-translational language activities}

And we have not even mentioned linguistic and cultural competence, which, of course, should be perfect. It goes without saying that a solid linguistic and cultural competence in both source and target cultures is not the object of, but a prerequisite for, translator training. If translation is taught too early, i.e. before the students have reached a sufficient command of language and culture, translation classes will degenerate into language acquisition classes without the students (or the teachers) even realizing.

On the other hand, students entering translator training do not normally come with sufficient language and culture competence, so that they have to attend language classes before starting to translate. In order to save time and effort, however, the development of language and culture competence should be specifically designed for translator training. As we all know, it does make a difference whether somebody learns a language for such practical purposes as, for example, finding their way in a foreign country without starving or getting into all sorts of trouble, or in order to be able to translate from or into this language. A part from the ability to communicate in the language (i.e. to understand texts that are read out or written and to produce texts which are apt to serve certain communicative purposes), translation requires a particular kind of metacommunicative competence, i.e. the knowledge about how the 
two languages and cultures work and where the differences lie that make it impossible just to "switch codes" in translation. Therefore, language teachers working in a translator training programme should be aware of the specificities of translational language use and take them into consideration.

It is a frequent complaint that translation students have an insufficient command of their own native language. A part from the development of foreign-language proficiency, translation-oriented language classes may also lead to a better competence in the native language if the contrastive perspective is introduced at a rather early stage. This does not mean that I would like to revive the old tradition of using translation as a teaching tool in foreign-language acquisition (as was typical particularly of $L$ atin and Greek classes). On the contrary, grammar translation (or: "philological translation") should definitely be banned from the translation-oriented language class. What is much more efficient is the contrastive analysis of authentic, real-life texts, which shows that similar communicative intentions are verbalized in different ways in the two cultures even though the language system may allow the use of analogous structures. This is what I would like to call "contrastive style analysis": students should be made aware of the norms and conventions of communication in everyday settings before they start translating structure-by-structure or word-by-word.

Parallel to the development of native and foreign language competence, the students should gain some insight into the following aspects of general text competence:

- text production as a purposeful, culture-bound activity (text pragmatics)

- $\quad$ texts as means of communication used for specific purposes and addressees

- $\quad$ the importance of cultural and world knowledge for both text reception and production 
- the extralinguistic restraints controlling text production (e.g. legal norms, corporate language, marketing policies)

- LSP and terminology as particular forms of communication in specific domains

In order to achieve these insights, the following exercises may be found useful:

- analysis and comparison of texts and discourse produced for different audiences (women - men, children - students - adults, specialists - laypersons) or transmitted by different media (oral written, written in traditional media - written in internet chatgroups), at different times (i.e. diachronical differences) or in different places (i.e. diatopical differences within one language area), identifying and evaluating text strategies,

- analysis and comparison of texts belonging to various text types or genres, identification of text-type conventions

- identification of function markers in texts or text segments

- spotting text defects

- revision of faulty or unfunctional texts, revision of translated or machine-translated texts, re-writing of deficient texts

- analysis of texts dealing with other cultures, identifying the methods used for providing cultural background information

- paraphrasing utterances and identifying the difference in use or communicative effect

- wordplay and punning, crossword puzzles ("creativity exercises")

- composing and structuring semantic fields, differentiating synonyms, defining word meaning and usage

- restructuring sentences (complex into simple, and vice versa)

- rewriting texts according to stylistic rules or instructions

- rewriting texts for other audiences, purposes, media, places etc. (= "intralingual translation")

- summarizing or abstracting long texts 
- $\quad$ converting nonverbal text elements (figures, tables, schematic representations, models) into verbal text (and vice versa), especially in technical communication

- produce written texts on the basis of oral information (or vice versa)

- revise deficient texts (= "quality management").

If these skills are acquised in the native language first and then applied to the foreign languages, contrasting native and foreign texts in a third step, the students will have learned a lot about translation without having translated yet. A the same time, they have developed their active and passive text competence both in the native and the foreign languages.

Contrastive text competence is the ability to analyse the culturespecific features of textual and other communicative conventions in two cultures. What is needed here, is a number of general parameters that may have different forms in the source and the target culture, for example:

- textual macro-strategies or types of argument, i.e. how the material is organized rhetorically (e.g., proceeding from general to particular or vice versa, stating a position to take issue with, BPSE = background, problems, solution, evaluation);

- theme-rheme progression (focus, emphasis, as in cleft sentence structures);

- cohesive devices (e.g., linkages, signalling, structure markers);

- metadiscourse, i.e. discourse that refers overtly to itself (i.e. "As we saw earlier...", "I will come back to this point later", also headings and subheadings indicating what is to follow in the text);

- attribution, i.e. the way things and phenomena are specified in the text (e.g., by an adjective, a prepositional phrase, a relative clause, a parenthesis);

- modalization, i.e. implicit expressions of speaker attitudes (e. g. , by subjunctive, modal particles, diminutives, word order), etc.

Text material should include mainly practice-oriented text types, such as business communication, computer manuals, software, 
product documentation, contracts, business and market reports, patents, image brochures, operating instructions, students' textbooks or scholarly articles, "EU texts", and the like.

- Teaching methods include

- parallel text analysis,

- bilateral and multilateral translation criticism,

- rewriting and text revision again.

It is important to note that contrastive text competence is not based on systemic contrastive linguistics, but on a comparison of "language in action", where the focus is on the form, frequency, and distribution of communicative acts.

\section{From theory to practice and back to theory: the "pigtail method" in the translator-training curriculum}

To train functional translators as described above, trainers need both practical and theoretical knowledge. They should know the skills and abilities that are required in the profession (= practical knowledge), and they should know how describe them using the concepts and terms of some kind of theory (= theoretical knowledge). To learn means to identify and recognize patterns of behaviour, relating them to a systematic framework, and to teach means to guide the students' attention towards relevant features, allowing them to discover the underlying regularities and giving names to the discovered phenomena.

There is often a debate on whether to start with theory (in a kind of land drill) or with practice (in a kind of swim-or-sink procedure). Personally, I am in favour of what I call a pig-tail method: starting out with a small portion of theory, which is then applied to practice, where the need for more theory becomes obvious, which is then satisfied by another portion of theory, and so on.

The land-drill procedure soon becomes sterile because when the students start practising they will have forgotten what they have 
learnt in theory, and the swim-or-sink procedure has the great disadvantage of risking that the students acquire bad translation habits which have to be cured afterwards.

The curricular structure of our training programme for technical translators ${ }^{1}$ follows this pig-tail philosophy:

$>1^{\text {st }}$ to $3^{\text {rd }}$ semester: introduction to the theoretical and methodological concepts of intercultural communication and translation;

$>4^{\text {th }}$ semester: introduction to translation practice of both general and specialized texts, into the native and into the foreign language, with constant references to the theoretical background;

$>5^{\text {th }}$ semester: practical periods and/or university studies abroad;

$>6^{\text {th }}$ and $7^{\text {th }}$ semester: practice and theory of specialized translation, terminology, use of both traditional and electronic translation aids and tools, practical part of the final exams;

$>8^{\text {th }}$ semester: diploma thesis and colloquium (i.e. theoretical part of the final exams).

The first theoretical phase includes the following activities:

- development of a (contrastive) language and culture competence in two foreign languages and in the native language, including the ability to produce texts for a variety of situations and functions (see section 3),

- introduction to translation-relevant aspects of linguistics and pragmatics in order to provide the concepts and terms needed for text and discourse analysis, and

- the basic concepts of intercultural communication and translation theory.

The introduction to translation theory is basically practice-oriented and deals with the most important aspects of professional translation, such as: translation as a purposeful activity, models of the translation process, communicative functions of texts and transla- 
tions, translation typologies, the role of norms and conventions in translation, the translation brief, translational analysis of source texts and target-culture parallel texts, translation problems and strategies to solve them, translation aids (including dictionaries). Since the course is compulsory for all students, independent of the foreign languages they have chosen for their training, the main languages used for examples and illustration are German and English (which they all know), but frequent references to distant cultures (A sia, L atin A merica) have proved to be of advantage to make the students aware of cultural distance and of the culture-specificity of their own behaviour. The theoretical concepts can also be introduced (at least in part) in the pre-translational language courses.

\section{How to design a translation task: source texts and target texts}

Before entering the practical stage of translator training, we have to make sure that the students have reached a sufficient level of language and culture competence, that they know how to use the main translation aids and tools, and that their theoretical knowledge of the basic concepts of translation and intercultural communication enables them to comment on translation procedures and strategies used by themselves or by others. If this is the case, translation practice - duly combined with back references to the theoretical groundwork, as suggested by the pig-tail model - should be geared towards a systematic development of transfer competence. This means that each translation task must be designed in such a way that it does not raise too many or too complicated translation problems. From the second translation task onward, the proportion of "familiar" translation problems that have been discussed before should be larger than, or at least equal to, the proportion of "new" translation problems. 
The difficulty of a translation task is influenced by the following factors:

- the complexity and degree of specificity of the source text (= source-text qualities),

- the number and quality of the translation aids provided with the task or easily available (= available documentation),

- the translation brief which specifies the intended functions, addressees, medium, quality standard, etc. of the target text (= translation brief), and

- the knowledge resources, skills and abilities of the translating person (= student's level of competence).

If a translation task is to be feasible for a particular student or group of students, this means

- that the source text should be selected bearing the students' level of competence in mind (because a text which is too difficult is not likely to motivate the students but rather will cause frustration and a feeling of failure),

- that every translation task should be accompanied by a translation brief (because it is easier to reach a well-defined goal than to poke about in the fog of what the teacher may have thought would be the target-text function), and

- that translation aids and tools (parallel texts, dictionaries, glossaries, encyclopedic material, internet search machines etc.) should be available and accessible during the translation process,

- the time limit and the required quality standard of the target text should be geared to the degree of difficulty of the translation task.

All of these factors may be used to increase or reduce the overall degree of difficulty in order to achieve a slower or more rapid learning progression may be increased slowly but steadily (= "learning progression") by increasing the difficulty of one or more parameters, according to the learning stage. If, for example, in the initial phase, the students have to translate a source text which is 
relatively complicated or of bad quality, there should at least be a sufficient amount of documentation available and the translation brief should not require a camera-ready equivalent translation but perhaps just a rough translation giving the main arguments of the text. In the advanced phase, however, the translation brief may ask for a perfect translation even of a complex or badly written source text. But beside perfection, efficiency, too, is a factor that has to be taken into consideration: in a limited length of time, it is more efficient to produce a decent translation of the whole source text than a perfect rendering of only the first half.

On the whole, selecting texts for translation classes is not a matter of adhering to rigid principles - nor is it a matter of mere intuition. It is a fundamental requirement in translation teaching that only authentic texts should be used as material, i.e. real texts-in-situation, and that they should be practice-relevant. This means that in a culture like Germany, where newspaper articles are hardly ever translated because the big newspapers have their own correspondents all over the world, newspaper texts play a secondary role in translation classes, if any - they may be quite useful when dealing with translation problems like culture-bound realities (realia) or citations. All source texts have to be presented to the students in such a way that as much information as possible is provided on the situation in which the original is or was used in order to make the task more realistic.

\section{Translation projects: role-playing and acquiring responsibility}

$M$ any of us may remember translation classes where a text was translated sentence by sentence, discussing all or most of the participants' suggestions and questions and ending up - after a few weeks! - with a translation that more or less conformed to the teacher's ideas of a "good" (or "correct" or "adequate" or 
"equivalent" or whatever standard was preferred at the time) rendering (cf. Nord 1996, 313). The main problem was that the text as a whole and as a purposeful instrument of communication never came into focus. D onald C. K iraly describes this situation as follows:

...the traditional learning environment created for the teaching of translation skills ... essentially involves a didactic performance by the teacher, who believes that she has access to the 'correct' translation, and who goes about filling in gaps in the students' knowledge so that they can also come up with the 'correct' translation. In such a classroom, it is clearly the teacher's job to "teach" - i.e. to pass on knowledge, and the students' job to 'learn', i.e. to absorb the teacher's knowledge. (Kiraly 1997, 152).

In modern translation practice, team work and management skills are qualifications required of any professional translator, whether she works for a translation agency or free-lance (mostly in a group of colleagues) or for a company. In the traditional translation classroom, these qualifications cannot be acquired. Therefore, translation practice during training should - at least in part - be organized in projects where each student has the chance to play various roles: that of client, or revisor, of terminologist, of documentation assistent, of free-lancer, of an in-house translator working for a translation company, etc. The teacher's role is that of a monitor and fire-brigade, but students learn to manage their translation projects autonomously, and, to a certain degree, they may even learn how to negotiate working conditions, fees or deadlines. In some exceptional cases, students may even work on real translation jobs required by real clients and get real money for it. The $\mathrm{M}$ agdeburg students spend their fifth semester abroad, working as interns in some kind of intercultural setting, many of them even have to perform translation jobs. 
Of course, if we want to teach in projects, the traditional university schedule (i.e. spending a certain amount of classroom hours per week, say: Tuesday from 2 to 4 p.m., on a particular task) has to be abandoned. But professional practice does not consist of spending two hours per week on one translation job, and two more hours on another, and so on, until 10 little jobs have been finished after 3 or 4 months. Professional practice means deadline pressure, working through nights and Sundays, and having half a day off on Thursday, if you are lucky. It is not necessary to organize translator training completely by projects, but each student should at least have had the experience of some project training, preferably in the advanced phases of the programme. One advantage of project teaching is that source texts may be longer (and thus more realistic!) than those dealt with in a classroom setting.

\section{Q uality control: monitoring the learning progress}

A long the lines of norms like ISO 9000ff. (1992) or DIN 2345 (1998), "quality control" and "quality management" are modern buzzwords in professional translation settings (cf. Schmitt 1998, 395), which should also be considered - at least to a certain extent - in translator training. In the translation projects, one role may be that of quality manager - and in the classroom, students have to become acquainted with the procedures of proof-reading and revising their own translations and those produced by other translators making use of the linguistic and translatological concepts they have learned in the preparatory course in order to justify their judgments.

M onitoring takes various forms in the different stages of the learning process. U sing a top-down strategy which proceeds from situational macrostructures to linguistic microstructures, pragmatic adequacy is more important than linguistic correctness in the introductory phase, whereas violations of stylistic and linguistic 
conventions and norms will carry more weight in the advanced phases of the training programme. The grading of cultural and linguistic errors depends on the influence they have on the function of the target text (cf. Nord 1997a, 76f.). If a missing comma or a spelling mistake leads to an inadequate interpretation of any of the intended functions, it is no longer a mere deviation from a linguistic norm but has pragmatic consequences (cf. Schmitt 1997, 306). In a translation where the referential function is predominant, the information given in the source text would have priority over any other function or sub-function. But in a translation where the appellative function is predominant, one might be justified playing down or even omitting certain information if it obstructs the intended appellative function.

A nother criterion for the grading of mistakes may be the effort needed to correct it in a revision process (cf. Schmitt 1997, 307). A wrong term which has been used consistently and can be corrected by a mere search-replace procedure of the text processing programme may be considered less relevant than a sentence structure reproduced from the source language which does not conform to target-culture style conventions and can only be corrected by restructuring the whole paragraph.

\section{From practice to theory and back to practice: application-oriented research in translator-training institutions}

As I mentioned before, translator trainers usually come from various backgrounds. They may have been language teachers or self-made translators or even bilingual engineers. This is not a bad thing in itself, and it may even be an inspiring contribution to the methodological discussions among the staff of a translator training department if the profession is looked at from a variety of perspectives. But for translator training it is not sufficient just to 
produce good translations, nor is it enough to know everything about language, pragmatics and linguistics (or even translation theory). The interplay of theory and practice may be more important in this area than anywhere else. Although translating as an activity has been around for more than two thousand years, translation studies is still striving for its recognition as a discipline in its own right. Therefore, the "pig-tail" procedure may also render good results for trainers: practitioners should not despise theory, while theoreticians might benefit from a "sabbatical" in a translation company, which may lead them to more specific theoretical insights.

$M$ oreover, in order to achieve the learning aims described in section 3 , we cannot rely on a large number of publications studying all the aspects of language-bound and contrastive text competence. Thus, there is a great need for application-oriented research in translator training, especially with regard to corpus-based, descriptive comparative studies on what is usually called "norms and conventions". Here is just a small glimpse on an extremely rewarding field of investigation and a selection of the studies that have been realized or are being worked on in translator training institutions so far:

- text-type conventions, e.g. titles and headings in German, English, French and Spanish (N ord 1993, 1994a, 1995); scientific and technical texts in German and English (Göpferich 1995), academic rhetoric in English and Finnish (M auranen 1993), pharmaceutical package inserts in Spanish and German (N ord 1999);

- style conventions, e.g. for the expression of modality in French and German (F eyrer 1997), for attribution, reported speech, cohesion etc. in Spanish and German (N ord 2001);

- conventions for the verbalization of certain communicative (sub)functions, e.g. for metacommunication in German, French and Spanish university manuals (cf. Nord 2000), topic-comment structures in German and French encyclopedic texts (Hirsch 1995), intertextuality (cf. N ord 1993, 189ff., W aismayer 2000), or references to realities of another culture (cf. Odenthal 1995); 
- conventions of non-verbal behaviour in real-life or fictitious situations, e.g. nonverbal or paraverbal behaviour in Alice in Wonderland and some of its translations into German, French, Spanish, Italian and Brazilian Portuguese (N ord 1994b, 1997b);

- translational conventions, e.g. how translators deal with proper names or quotations, whether, in which cases and how often they prefer source-culture reproduction to target-culture adaptations, etc.

There are questions to study and corpora to analyze for many generations of students and teachers to come. Today's critical students no longer silently agree if you tell them that this or that is the way "you" or "people" express a particular function in a particular text type or situation - they find their own ways of expressing just as appropriate (or even better). And it is really not very motivating to play the "age card" (the teacher is al ways older than the students, and therefore she/he is right!). By the way, conventions are subject to change, so maybe the students are right, and your own way of expressing yourself is completely obsolete or at least hopelessly old-fashioned.

Therefore, the best method to motivate students (and trainers) to take up application-oriented research is to discuss norms and conventions of any kind of verbal or nonverbal behaviour and let them see for themselves what they are like. And if the results of these studies, however limited their range may be, flow back directly into training, they will make better students and better trainers, and translation classes more efficient. ${ }^{2}$ 


\section{Notes}

1. The following details refer to the four-year Programme for "Specialized Communication" at the U niversity of A pplied Sciences (F achhochschule) of M agdeburg, Germany, which started in 1964 and leads to a German Diploma degree corresponding to a British Bachelor H onours or a Spanish Licenciatura.

2. This article will al so be published as a chapter in M artha Tennent (ed.): Training Translators for the N ew M illenium, A msterdam: John Benjamins (2001).

\section{R eferences}

A gar, M ichael (1991) The Biculture in Bilingual, in: Language in Society 20:167181.

Din 2345: 1998-04: Übersetzungsaufträge. DIN EN ISO 9004-2: 1992-06: Qualitätsmanagement und Elemente eines Qualitätssicherungssystems - Teil 2: Leitfaden für Dienstleistungen.

F eyrer, Cornelia (1997) M odalität im Kontrast: Ein Beitrag zur übersetzungsorientierten Modalpartikelforschung anhand des D eutschen und des Französischen, Frankfurt/ $M$.: Peter Lang.

Göpferich, Susanne (1995) Textsorten in Naturwissenschaft und Technik: Pragmatische Typologie - Kontrastierung - Translation. Tübingen: Narr (= F 0rum für $\mathrm{F}$ achsprachenforschung 27).

Hirsch, Claudia (1995): Die Thema-Rhema-Gliederung in deutschen und französischen Fachtexten am Beispiel von Sachwörterbuchartikeln, unpubl. Diploma Thesis, U niversity of Hildesheim/G ermany. 
Kiraly, D onald C. (1997) Collaborative L earning in the Translation Practice Classroom, in: E. Fleischmann, W. Kutz, Peter A. Schmitt (eds.) Translationsdidaktik, Tübingen: N arr, 152-158.

M auranen, A nna (1993) Cultural Differences in Academic Rhetoric, Frankfurt/ $M$ ain: Peter Lang.

Nord, Christiane (1993) Einführung in das funktionale Ü bersetzen. Am Beispiel von Titeln und Ü berschriften, Tübingen: Francke (= UTB 1734).

Nord, Christiane (1994a) Functional U nits in Translation, in: Anna M auranen \& Tiina Puurtinen (eds.) Translation - Acquisition - Use, Jyväskylä: U niversity Press, 41-50.

N ord, Christiane (1994b) It's Tea-T ime in W onderland: culture-markers in fictional texts, in $\mathrm{H}$. Pürschel et al. (eds.) Intercultural Communication, Frankfurt: Peter L ang, 523-538.

N ord, Christiane (1995) Text-functions in translation. Titles and headings as a case in point, Target 7:2 (1995), 261-284.

Nord, Christiane (1996) Wer nimmt denn mal den ersten Satz? in: A . L auer et al. (eds.) Translationswissenschaft im U mbruch. Festschrift für Wolfram Wilss, Tübingen: Narr, 313-327.

Nord, Christiane (1997a) Translating as a Purposeful Activity, Manchester: St. Jerome.

N ord, Christiane (1997b) A lice A broad: D ealing with descriptions and transcriptions of paralanguage in literary translation, in Fernando Poyatos (ed.) Nonverbal Communication and Translation, A msterdam: Benjamins, 107-129.

Nord, Christiane (1999) Der A dressat - das unbekannte Wesen? M öglichkeiten und Grenzen der Adressatengerechtheit beim Übersetzen, in A lberto Gil et al. (eds.) M odelle der Translation, Frankfurt/M ain: Peter Lang, 192-207. 
Nord, Christiane (2000) Das hinkende Beispiel und andere M erk-W ürdigkeiten. $M$ etakommunikation in deutschen, spanischen und französischen $L$ ehrbuchtexten, in Gerd Wotjak (ed.): Akten der IV. Internationalen Tagung zum romanischdeutschen und innerromanischen Sprachvergleich Leipzig 1999 (forthcoming).

Nord, Christiane (2001) Kommunikativ handeln auf Spanisch und Deutsch. Ü bersetzungsorientierter Sprach- und Stilvergleich, W ilhelmsfeld: Gottfried Egert (forthcoming).

Odenthal, Cordula (1995) D ie Übersetzung spanischer Realienbezeichnungen ins Deutsche. Eine textsortenspezifische Untersuchung, unpubl. Diploma Thesis, University of Hildesheim/Germany.

Schmitt, Peter A . (1997) Evaluierung von Fachübersetzungen, in: G. Wotjak, H. Schmidt (eds.) Modelle der Translation - Models of Translation, Frankfurt/M .: Vervuert, 301-332.

Schmitt, Peter A . (1998) Q uali iätsmanagement, in: M ary Snell-H ornby et al. (eds.) Handbuch Translation, Tübingen: Stauffenburg, 394-399.

Waismayer, M artha (2000) Intertextualität in deutschen und britischen P ressetexten, unpubl. Diploma Thesis, U niversity of V ienna. 